Mote: «e nas nossas costas cairão nomes como pedras»

\title{
Trans-resistências:
}

\section{Entre Novas Cartas Portuguesas (1972) e Trans Iberic Love (2013)}

\author{
Anna M. Klobucka \\ UMass-Dartmouth
}

O meu contributo para esta mesa redonda, orientada pelo mote "e nas nossas costas cairão nomes como pedras" - mais adiante voltarei a esta frase e ao fragmento das Novas Cartas Portuguesas em que se insere - não é propriamente uma comunicação acabada nem, muito menos, um registo exaustivo e organizado da comparação dos dois textos que tenciono aqui confrontar. Trata-se, antes, de esboçar uma releitura retrospetiva das Novas Cartas - ou melhor, de alguns elementos e ângulos deste livro inesgotavelmente polivalente - através do filtro analítico proporcionado por um outro texto que se situa numa relação política comparavelmente direta e também intencionalmente interveniente para com o seu contexto político e social (contexto que é o da atualidade da segunda década do século XXI), 
ao mesmo tempo que aborda muitas das preocupações centrais das Novas Cartas - como a igualdade de género e a justiça social - numa perspetiva que o livro das Três Marias eventualmente prefigura, eventualmente desconhece e eventualmente desconhece enquanto prefigura (a meu ver, todos estes diagnósticos coexistem no campo da plausibilidade hermenêutica que não poderei explorar aqui plenamente). Trata-se, portanto, de tentar perceber em que medida um texto representativo da vivência da realidade portuguesa e europeia pela chamada "geração à rasca" será capaz de infletir produtivamente a nossa perceção e interpretação do livro emblemático da vivência do salazarismo tardio por mulheres e outros sujeitos sociais esmagados pela ideologia e prática política do Estado Novo.

Trans Iberic Love, romance de estreia da cineasta e ativista Raquel Freire, foi lançado em junho de 2013, precisamente 40 anos depois do auge da notoriedade internacional das Novas Cartas Portuguesas que se seguiu à sua publicação em 1972 e à ação judicial movida contra as autoras. O romance conta uma história de amor entre Maria, uma mulher portuguesa de trinta e poucos anos, cisgénero (esta identificação, inexistente no horizonte epistemológico das Novas Cartas, é crucial em Trans Iberic Love), e um jovem transgénero, José batizado Eva, filho de um casal franco-espanhol, radicado em Barcelona. Ambas ou ambos combinam trabalho intelectual com ativismo político direcionado para uma "revolução pendente", com recurso aos meios tecnológicos e económicos ao seu alcance na época contemporânea: "Sem internet e sem aviões low cost, como faríamos a revolução pendente?" (Freire 2013: 66). (Um parêntese necessário sobre "ambas ou ambos": não sei pronunciar este pronome quando aparece grafado com x no lugar da vogal "a" ou "o" e portanto não posso representar fielmente a materialidade do texto de Trans Iberic Love numa comunicação oral; uma reflexão derrideana sobre este aspeto da narrativa terá de ficar para uma outra ocasião.) De uma maneira análoga ao que acontece nas Novas Cartas, o objetivo situado da contestação política de José - e de Maria, em adesão contingentemente solidária à causa do amado - que foca os direitos das pessoas transgénero (em particular, o direito à autodeterminação da identidade de género e a rejeição da obrigatoriedade dos protocolos médicos e jurídicos que gerem a mudança de sexo), insere-se numa rede muito 
mais vasta de afinidades políticas que José descreve da forma seguinte numa das muitas reiterações doutrinárias que pontuam o texto do romance:

Queremos mais. O nosso nome é secreto. Estamos abertos a todos os grupos e pessoas que se identifiquem como revolucionários, feministas e anticapitalistas. (...) A cooperação entre os estados e as grandes corporações para manter o capitalismo a funcionar tem que ser derrotada pela união e cooperação de todas as pessoas exploradas e oprimidas do mundo. (...) As mais belas flores nascem do lixo. Construímos uma rede de activistas. Durante o encontro europeu vamos finalmente ter a oportunidade de dialogar com todos os movimentos sociais e organizações radicais. Yes we can. (idem: 66-67)

Como esta citação permite perceber, Trans Iberic Love aproveita-se liberalmente da retórica dos movimentos de alterglobalização, autosituando-se cronologicamente, ainda, na era pós-Anonymous ("O nosso nome é secreto") e pós-eleição de Barack Obama nos Estados Unidos ("Yes we can"). Mas para além destas referências específicas, o excerto citado transmite também, de uma maneira eficaz, a ideia da forma estética que corporiza a performatividade política de Trans Iberic Love: é uma poética de sampling que se alimenta dos memes multilíngues e viralmente disseminados da cultura globalizada do século XXI. A fragmentariedade polimorfa e multidirecional das Novas Cartas foi gerada por uma tecnologia distinta da produção do sentido, mas é notável até que ponto as técnicas desenvolvidas pelas Três Marias antecipam o tecido comunicacional patente neste e noutros textos, nem todos em forma de livro, que veiculam os significados da nossa atualidade "40 anos depois". (E estou a pensar aqui na técnica de sampling, mas também nas práticas de comunicação dialógica patentes nas redes sociais, por exemplo.)

Haveria muito que dizer sobre os paralelos e as diferenças entre os dois livros no que diz respeito ao posicionamento geocultural das histórias de amor trans-fronteiras que ambos narram. Ao eixo bilateral e hierarquizado luso-francês da relação entre Mariana e o cavaleiro substitui-se aqui uma rede assaz horizontal de afinidades principalmente ibéricas entre Maria e José, rede que inclui identificações culturais periféricas dentro da própria Ibéria, como é o caso do mirandês (a avó de Maria era mirandesa e alguns versos de uma canção em mirandês a tocar "na musicbox da [sua] cabeça" - expressão que se torna 
recorrente no livro - funcionam como um dos refrãos da narrativa). Por sua vez, a mistura intercultural dos ascendentes de José conta também com uma avó galega. De facto, sob este aspeto, o modelo intertextual mais clara e explicitamente relevante para Trans Iberic Love será antes Jangada de Pedra de Saramago - título e autor várias vezes evocados no romance - do que as Lettres portugaises ou as Novas Cartas Portuguesas. E o amor entre Maria e José é várias vezes comparado à paixão de Blimunda em Memorial do Convento (Baltazar, curiosamente, não é mencionado), numa apropriação irónica das paisagens amorosas firmemente heteronormativas de Saramago: "Somos 2 bichxs. Bichxsblimundas" (Freire 2013: 156).

Mas a faceta comum e divergente de Trans Iberic Love e Novas Cartas Portuguesas em que principalmente me quero deter é a que é sugerida pelo nosso mote, ou melhor, pela frase completa que encerra este fragmento no texto das Novas Cartas: "E virá quem agrida e de todos os lados surgirão gumes e farpas e nas nossas costas cairão nomes como pedras; mas putas ou lésbicas, tanto se nos faz que nos nomeiem, desde que se lute e não se perca" (Barreno/Horta/Costa 2010: 285). A frase aparece no "Texto de honra ou de interrogar, escrito por uma mulher de nome Joana" que alterna entre perguntas ("Pergunto") e afirmações ("Digo") e cuja autora acaba o seu discurso com uma chamada à ação: "Digo: Chega. É tempo de se gritar: chega. E formarmos um bloco com os nossos corpos" (idem: 286). Esta última citação encaixar-se-ia perfeitamente no romance de Raquel Freire, como também caberia nele - aliás cabe, efetivamente - a relação causa-efeito em que a um insulto de base identitária ("putas ou lésbicas") se segue uma afirmação orgulhosa dessa mesma identificação, afirmação representada explicitamente como um ato de resistência. Assim, num episódio que decorre em Barcelona, José - que assume uma imagem masculina e atração sexual por mulheres - é chamado de "maricas" e "paneleiro de merda" por um grupo de bêbados que o veem abraçar carinhosamente um amigo. José responde assumindo a identidade pressuposta pelo insulto - "Está a falar comigo? Sou paneleiro, sim senhor, e depois?" (Freire 2013: 48) - e, depois de ser espancado em resultado deste desafio, faz queixa contra os agressores por "homofobia, agressão, insulto, ameaça à integridade e à liberdade" (idem: 49), ao mesmo tempo que reconhece o seu posicionamento como 
"irónico", uma vez que "Sempre gostei de mulheres. Sempre me vi como um feminista. Um feminista lésbica" (idem: 49). Em outro passo do romance, a afirmação identitária, construindo-se igualmente como um efeito situacional da resistência, leva José a realçar, pelo contrário, a sua "parte feminina" (idem: 50). Recordando a sua identidade aos olhos de familiares, de "criança ... hiperactiva, genialmente inteligente e boa aluna, o geniozinho da família" (ibidem), José ironiza sobre a masculinidade obrigatória da noção do génio - "não existem génias, existem génios" - observando que neste caso não se verificava nenhuma oposição da família à modificação simbólica do género da filha: "Eu sou um génio, um pequeno génio, aqui o género masculino já não lhes faz confusão, é uma coisa séria" (ibidem). Neste contexto, portanto, José autoposiciona-se politicamente do lado do feminino desvalorizado:

Como a linguagem é sexista e misógina e machista e binária e hetero-sexista e patriarcal e é nestas alturas que a mulher que há em mim fala mais alto e me dá ... este orgulho na parte feminina de mim. (ibidem)

É devido a esta faceta de Trans Iberic Love que o texto de Raquel Freire se me afigura como uma ferramenta potencialmente útil para uma revisitação das noções de resistência e identificação - ou seja, identidade entendida como processo - nas Novas Cartas Portuguesas. Se em Trans Iberic Love as afirmações identitárias se verificam sempre fluidas e instáveis mas, ao mesmo tempo, sempre politicamente situadas e conscientes da sua pretendida eficácia política, como se configuraria, neste registo, o texto das Três Marias? Dada a reflexão que já realizei no passado, no artigo intitulado “'Considerai, irmãs minhas': As negociações de parentesco e comunidade entre as Lettres portugaises e as Novas cartas portuguesas", estou a pensar aqui principalmente na identificação lésbica, mas haverá obviamente outras trans-resistências e trans-identificações por interrogar neste texto que nos continua a ocupar, inspirar e perturbar "40 anos depois". 


\section{Bibliografia}

Barreno, Maria Isabel/Maria Teresa Horta/Maria Velho da Costa (2010), Novas Cartas Portuguesas, Edição Anotada, Org. Ana Luísa Amaral, Lisboa, D. Quixote.

Freire, Raquel (2013), Trans Iberic Love, Lisboa, Divina Comédia.

Klobucka, Anna M. (2012), “'Considerai, irmãs minhas': As negociações de parentesco e comunidade entre as Lettres portugaises e as Novas cartas portuguesas", Cadernos de Literatura Comparada 26/27, 41-59.

Anna M. Klobucka é professora nos Departamentos de Português e de Women's and Gender Studies da Universidade de Massachusetts Dartmouth (EUA). É autora de $O$ Formato Mulher: A Emergência da Autoria Feminina na Poesia Portuguesa (Angelus Novus, 2009) e Mariana Alcoforado: Formação de Um Mito Cultural (IN-CM, 2006; ed. original Bucknell University Press, 2000). Co-organizou os volumes After the Revolution: Twenty Years of Portuguese Literature 1974-1994 (com Helena Kaufman; Bucknell, 1997); com Mark Sabine, o Corpo em Pessoa: Corporalidade, Género, Sexualidade (Assírio \& Alvim, 2010; ed. original University of Toronto Press, 2007); e com Hilary Owen, Gender, Empire and Postcolony: Luso-Afro-Brazilian Intersections (Palgrave Macmillan, 2014). 